\title{
Multi-agent Modeling of the Collaborative Operation of the Producer Service Supply Chain under the Intelligent Manufacturing Clusters in the Yangtze River Delta
}

\author{
Caihong Liu \\ School of Business, Jiaxing University, Jiaxing 314001, China
}

Corresponding Author Email: rainbowliu@zjxu.edu.cn

https://doi.org/10.18280/jesa.530406

Received: 9 April 2020

Accepted: 17 July 2020

\section{Keywords:}

intelligent manufacturing, producer service supply chain, collaborative operation, multiagent modeling

\begin{abstract}
With the proliferation and aggregation of advanced production technology and information technology, several regional intelligent manufacturing clusters have taken shape in China. The development of intelligent manufacturing, which is highly technical, innovative, and informatized, needs the support of more professional producer services. Considering the broad scope of producer service supply-demand in regional intelligent manufacturing, this paper takes the intelligent manufacturing cluster in the Yangtze River Delta as the object, analyzes the limited access to producer services required for production operations, and proposes to integrate and supply the resources of multiple service agents in the region in a dynamic and collaborative manner. Then, the Multi-Agent model was constructed for the producer service supply chain, and the relevant factor libraries and decision libraries were designed. Finally, an empirical analysis was carried out to evaluate the stability of the collaborative operation of the producer service supply chain under the effect of some collaboration factors. The results show that the model has a certain theoretical reference value.
\end{abstract}

\section{INTRODUCTION}

The manufacturing industry is faced with new challenges from global competition, demand individualization, and intelligent manufacturing. To adapt to the fast-changing market, the producer service industry, which enables manufacturers to focus on their core business, is increasingly refined and professional in the division of labor. A growing attention has been paid to create more values by effectively integrating the producer service industry with manufacturing.

Intelligent manufacturing is a mixed blessing for Chinese manufacturers. On the one hand, intelligent manufacturing provides the manufacturing industry a golden opportunity for transformation and upgrading; on the other hand, the supply chain of the industry becomes more uncertain in the new environment of intelligent manufacturing. Tjahjono et al. [1] held that the Fourth Industrial Revolution (Industry 4.0) brings more risks of uncertainty than opportunities to supply chain.

Moreover, each enterprise, as an independent legal entity has its own interests. Hence, the division of labor and correlations between enterprises will induce information asymmetry among them. In particular, the lack of communication between supply chain enterprises in an industrial cluster magnifies the imbalance of production capacity and resource allocation in the supply chain. Without an effective coordination mechanism, the operational efficiency of the supply chain will enter a downward spiral, posing various challenges to the development of the industrial cluster (e.g. the insufficient and untimely allocation of producer service resources). The information asymmetry, coupled with the high uncertainty in the operating environment, creates new risks to the manufacturing industry. For this reason, it is necessary to prevent information asymmetry and uncertain operating environment from generating new risks. This highlights the importance of supply chain collaboration in intelligent manufacturing, which provides a guarantee to the operation efficiency of the supply chain.

Finally, from a realistic perspective, the clustering of enterprises will increase specialization and division of labor, and promote the trust and social regulation of enterprises. In fact, the clustering of manufacturing is an effective way to form a distinctive regional economy [2].

The Yangtze River Delta is the pioneer and leader of intelligent manufacturing in China. Most areas in the delta have similar foundations, consistent needs, and complementary resources, providing the basis and motive for collaborative development. As a result, the Yangtze River Delta is growing into a world-class cluster of intelligent manufacturing. This industrial cluster of advanced manufacturing boasts concentrated elements, complete structure, close cooperation, and obvious competitive advantages. However, the delta lacks top-level industries or technological fields in the global value chain, and exhibits weak collaboration capability and strong industrial homogeneity. To promote the economic strength, balance the economic growth, and realize leapfrog industrial development, it is of far-reaching importance to explore the coordinated and balanced development, and investigate the industrial linkage and cooperation of the delta [3].

The regional collaboration of manufacturing is the top priority for the delta. Under the demand for collaborative innovation of intelligent manufacturing, the manufacturing chain and the service chain of the Yangtze River Delta will be deeply integrated, in order to seize opportunities and establish dominance in industrial development and achieve regional 
coordinated development. Nevertheless, there are still many difficulties for the producer service supply chain that spans across administrative regions, such as the unclear operating standards, technical codes, support policies, and integration contents, as well as the chaotic scheduling of resources. Against this backdrop, it is very meaningful to research the collaborative operation of the producer service supply chain, which helps to expand the boundaries of the producer service and encourage intelligent manufacturers to integrate along the producer service supply chain, turning China into a large and strong manufacturer [4].

In this paper, the intelligent manufacturing cluster in the Yangtze River Delta, one of the most developed regions in China, is selected as the research object. Starting from the producer service demand and current state of producer service supply chain, the authors modeled the collaborative operation of the producer service supply chain under the theme of intelligent manufacturing, and carries out simulation with the established model.

\section{LITERATURE REVIEW}

To a certain extent, intelligent manufacturing directly drives enterprise collaboration and supply chain collaboration. In return, collaborative operation promotes the in-depth development of intelligent manufacturing [5].

\subsection{Intelligent manufacturing cluster}

The development of intelligent manufacturing has attracted great academic interest in intelligent manufacturing clusters. Goldfarb and Trefler [6] were the first to scrutinize intelligent manufacturing under the light of industrial clusters, pointing out that intelligent manufacturing has the effects of economies of scale and intensive knowledge. They also discussed the policies on intelligent manufacturing clusters. Yu [7] interpreted the theoretical connotations of world-class intelligent manufacturing cluster in four dimensions (i.e. enterprise, industry, region, and network organization), and clarified the upgrade mechanism of the intelligent manufacturing cluster that integrates the four dimensions in space. The European Commission (2010) formally defined the world-class industrial cluster as an ecosystem that promotes enterprise innovation, regional development, and international competitiveness at a world-class level, and specified a total of 15 attributes in 3 categories for world-class industrial clusters [8].

Some scholars have defined world-class industrial clusters from the perspective of obtaining competitive advantages and realizing world-class manufacturing $[9,10]$. For example, Faller and Feldmüller [11] studied the method to optimize and upgrade the intelligent manufacturing in clusters of small and medium enterprises (SMEs) in Germany. Giret et al. [12] proposed an intelligent manufacturing system for servicebased enterprise clusters. Focusing on advanced manufacturing clusters, Zhen [13] considered enterprises as network nodes, enterprise relationships as the edges between nodes, and the technology, intelligence, capital, service, and material within the cluster and on external platforms as the fluid between the nodes, highlighting the community ecological effects of network connections and interactions between the nodes.

Currently, most scholars are concerned with world-class intelligent manufacturing clusters, and SME intelligent manufacturing clusters, paying little attention to regional manufacturing clusters. In 2018, The Initiative on the Collaborative Innovation and Development of Intelligent Manufacturing in the Yangtze River Delta was released, marking the founding of an alliance in the delta for the collaborative innovation and development of intelligent manufacturing. This has positive significance for the delta to build a world-class intelligent manufacturing industry cluster, and lead the development of intelligent manufacturing.

\subsection{Producer service supply chain}

To serve the product manufacturing process, the producer service imports productive factors into the production and operation of the manufacturing industry. As the crux of global industrial competition, the producer service development can improve overall productivity and reduce the supply cost of the producer service industry [14]. The producer service emphasizes on a certain link or aspect in the production process, namely, the research and development (R\&D) of new products and new technologies [15].

The producer service supply chain carries the supply of the producer service, and covers all activities related to after-sales service [16]. From supplier service to consumer service, the information flow, service flow, capital flow, service process, and service performance are managed in an integrated manner on the producer service supply chain [17]. With the servitization of the manufacturing industry, it is inevitable for the supply chain for manufacturers to be servitized. Both the producer service industry and the manufacturing industry are based on the division of labor and the distribution of factors. Therefore, the development and maturity of the producer service industry can bolster the growth of the manufacturing industry, and promote the upgrading of the industrial structure [18].

Johnson and Mena [19] conceptualized the supply chain for product-service system (hereinafter referred to as productservice supply chain) as a hybrid model of product supply chain and service supply chain, involving both product flow and service flow. Bains et al. [20] suggested that the productservice supply chain needs to focus on the integration of service capabilities, aiming to provide consumers with a better product-service system. Lockett et al. [21] regarded productservice supply chain as a functional network to deliver product-service system to consumers. Schmenner [22] held that the integrators in the product-service supply chain can better satisfy the consumer demand for product and service by integrating upstream capabilities. The networking, virtualization, and collaboration of producer service operations have made it possible to forge a manufacturing producer service supply chain, which is flexible, efficient, and low-cost.

\subsection{Supply chain collaboration}

In recent years, the global market is continuously expanding, and the core competitiveness of enterprises is increasingly concentrated. In this background, the enterprises, which are independent legally and economically, have started to integrate their behaviors to optimize their operations and decision-making. The effect of behavioral integration hinges on the cooperation between enterprises and the coordination of logistics decision-making [23], both of which have attracted 
much attention from the academia and the industry.

Supply chain collaboration is the mutual effort of all node enterprises to coordinate the supply chain [24]. Frascatore and Mahmoodi [25] explored the collaboration and penalty contract in a two-stage supply chain composed of manufacturers and suppliers, revealing that penalty contract can promote supply chain collaboration more effectively than long-term contract. From the angle of knowledge innovation, Samaddar and Kadiyala [26] analyzed the coordination mechanism of resource sharing in cross-organizational supply chain. To disclose the impact of disruptive accidents on supply chain collaboration, Yu et al. [27] measured the influence of supply interruption under two random variable distribution functions on the supply chain system, drawing on the incentive mechanism of negative collaboration, and proposed a possible coordination mechanism for supply interruption, providing inspirations to managers from the perspective of supply chain risk management. Based on consumer service and game theory, Boyaci and Gallego [28] discussed the competition between two supply chains in three different scenarios: both choose noncollaboration, one chooses noncollaboration, and the other one chooses noncollaboration.

Thanks to the latest progress in knowledge and theory, the research methods of supply chain collaboration have been greatly improved. Inspired by social network theory, Lee [29] found that the supply chain performance is positively correlated with its degree of coordination. Supply chain collaboration has also been investigated with novel methods like neural network (NN) [30], Petri net, finite state machine (FSM), etc.

Each industrial cluster is a complex system with many parts. The different parts interact irregularly the individual (micro) level, and exhibit regular nonlinear results on the overall (macro) level. The Agent-based modeling provides a suitable method to study such a complex system [31, 32]. The MultiAgent system is composed of a group of autonomous, goaloriented Agents that interact with each other (Agent-to-Agent) or with the simulation environment (Agent-to-environment). These Agents can be assigned specific attributes, which are combined with the rules of the model (e.g. Agent behavior, decision-making, and interaction with the environment) to produce certain behaviors [33]. With good autonomy, responsiveness, and social features, Multi-Agent modeling is a desirable technology to explore the supply chain system, which is complex, autonomous, distributed, parallel, and dynamic, providing an effective way to solve the coordination and optimization of supply chains.

\section{MODEL CONSTRUCTION}

\subsection{Integrated service system for producer service supply chain}

The producer service for intelligent manufacturing clusters is a new high-tech and knowledge-intensive service industry in high-tech development zones. The highly integrated producer service supply chain empowers manufacturers to share resources and complement each other's advantages, enhancing the regional capability of collaborative innovation. The producer service system of intelligent manufacturing clusters, which feature high networking, digitization, and intelligence, is often constructed by a third party independent of the enterprises in the cluster.
The service collaboration system provides indispensable supports to the development of intelligent manufacturing. The producer service supply chain lies in the upstream of the manufacturing industry. Compared with the traditional supply chain, the producer service supply chain for intelligent manufacturing emphasizes the provision of high-tech, knowledge-based collaborative innovation service flow, capital flow, collaborative decision-making information flow, human capital flow, high-tech flow, knowledge flow, and resource matching flow around the concept of product manufacturing.

The configuration and scheduling of collaborative workflows is a challenging problem, due to its computational complexity, distributed architecture, and dependencies between the workflows of different partners [34]. By multiagent modeling, the investor of each service flow was treated as an agent, and each enterprise in the intelligent manufacturing cluster was also regarded as an agent. These agents interact and collaborate with each other on the integrated service system (Figure 1), forming an integrated producer service supply chain.

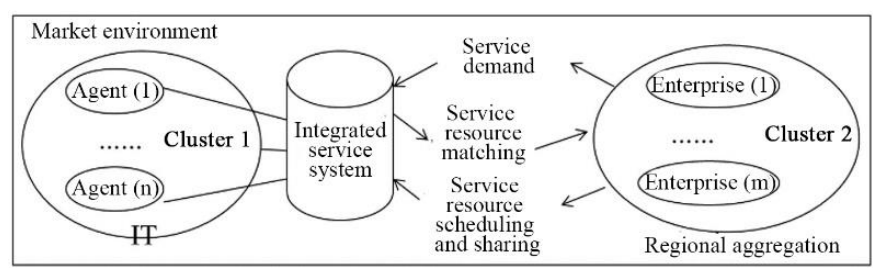

Figure 1. The Multi-Agent based operation diagram of the integrated service system for producer service supply chain

As a Multi-Agent system, the producer service supply chain can be represented by different agents. In Figure 1, Agent(1)Agent(n) represents a producer service supply chain with multiple functions; Cluster 1 represents the clusters of various service providers; Cluster 2 represents the regional clusters of intelligent manufacturers.

The integrated service system acts as a collaborative platform for the producer service supply chain. On that platform, the two kinds of clusters can operate collaboratively through service demand issuance, service-resource matching, as well as service scheduling and sharing.

\subsection{The structure of Multi-Agent-based producer service supply chain}

There is a loose distributed relationship between various producer service supply chains. The multiple collaborative relationships between manufacturers and service providers, between manufacturers, and between service providers are also dynamic and open. Strategically speaking, in the environment of intelligent manufacturing, the producer service collaboration network involves both the horizontal relationship between homogeneous nodes, and the vertical relationship between heterogeneous nodes. Tactically speaking, only when collaborative service activities are triggered, the strategic service supply-demand relationship will change from a strategic relationship to a realistic collaborative relationship, and form a realistic service supplydemand subnet in a dynamic manner.

Once a supply-demand task is completed, the relationship between relevant nodes will return to the loose distributed state. The node resources are not monopolized by any single task, 
reflecting the openness of the resource network and the flexibility of resource allocation in the producer service supply chain. This also indicates that the members of the producer service supply chain for intelligent manufacturing do not form any alliance. The collaboration between them terminates right after the completion of task. The members will be regrouped according to new demand. This dynamic collaborative relationship ensures the flexible and optimal allocation of producer service resources in the region.
In addition, the Multi-Agent system boasts cluster intelligence, owing to the communication, negotiation, and collaboration between multiple agents. Whereas the collaborative services involve complex information processing, information interaction, reasoning, and decisionmaking, a hybrid agent structure was adopted, including a sensor (perception) part, a decision (cognitive processing) part, and a fitness evaluation (response) part. Based on Figure 1, the structure of each service Agent was modelled as Figure 2.

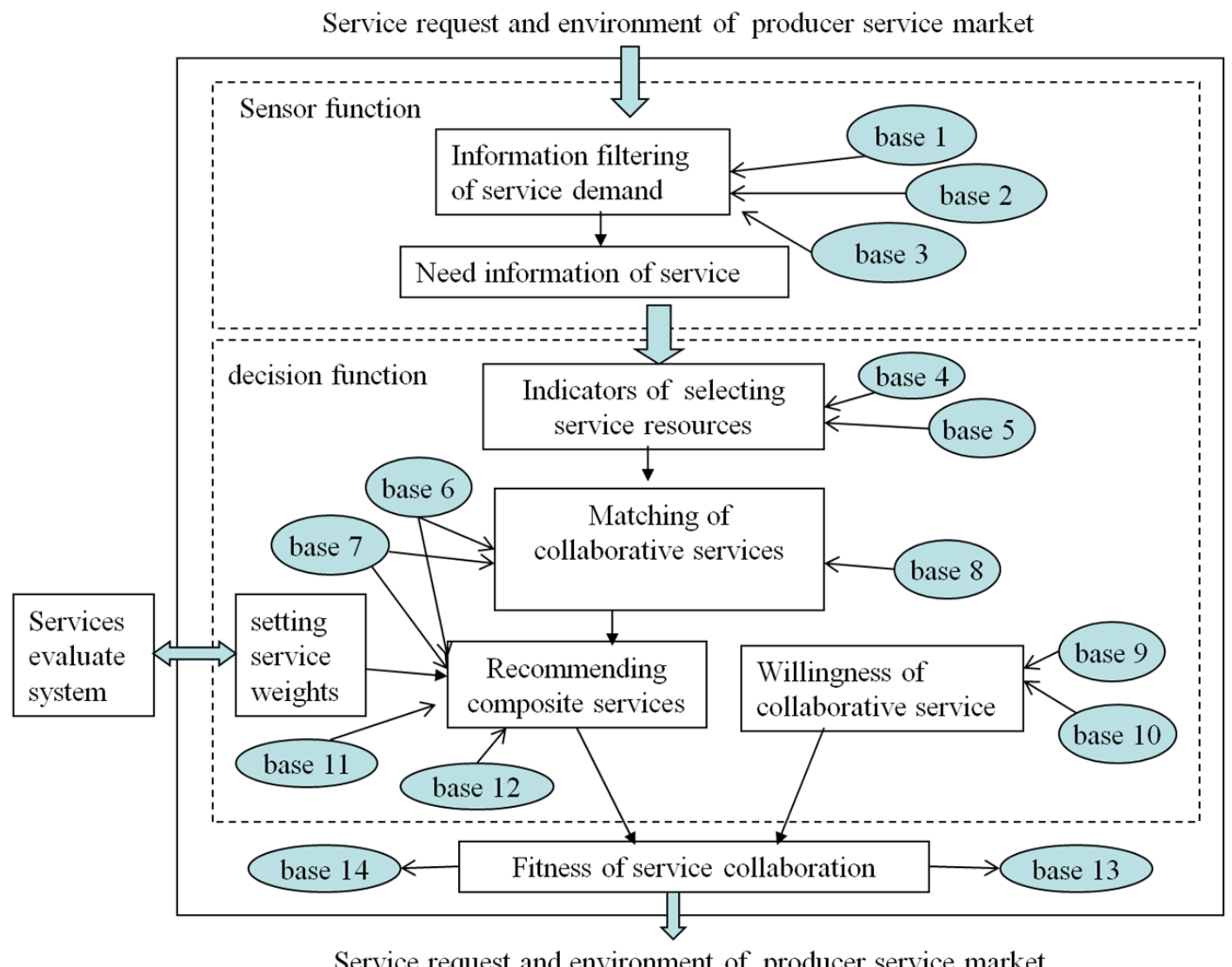

Figure 2. The service-oriented Agent model of producer service supply chain in cluster collaborative service system

As shown in Figure 2, each service-oriented Agent consists of a sensor part, and decision part, and a fitness evaluation part. Bases 1-13, the feature bases of producer services for the intelligent manufacturing cluster, are respectively, the base of service classes, the first base of cases, the base of service resource states, the base of dynamic adjustment rules for collaborative relationships, the base of decision rules, the base of knowledge, the base of service supply-demand relationships, the base of third-party service providers, the base of manufacturers, the base of combination rules, the base of risk control rules, the second base of cases, and the base of operation states. The formal descriptions of the 14 bases in Figure 2 are provided below:

(1) Base 1: =< Base ID, Service Demand Feature ID, Service Requester ID, Demand Responsiveness, Service Provider ID, Collaboration Capability of Service Provider, Credit of Service Provider, Expansion Base>.

(2) Base 2: =< Base ID, Service Class ID, Class Name, Functionality, Service Distribution State in the Region, Owner, Expansion Base>.

(3) Base 3: $=<$ Base ID, Service Instance ID, Operation Conditions of Instance, Satisfaction with Multi-Party
Collaboration, Influence on Intelligent Manufacturing, Expansion Base>.

(4) Base 4: $=<$ Base ID, Service Resource ID, Usage State ID, Service Resource Quality, Quantity State of Service Resource (Sufficient: 1 or Scarce: 0), Resource Owner ID, Resource Owner Name, Credit of Resource Owner, Expansion Base $>$.

(5) Base 5: $=<$ Base ID, Collaborative Service ID, Supplier ID, Demander ID, Supply-Demand Relationship, Response Time, End Time, Number of Responses, Expansion Base >.

(6) Base 6: $=<$ Base ID, Inference Path ID, Parameter Set, Inference Path, Expansion Base >.

(7) Base 7: $=<$ Base ID, Knowledge ID, Knowledge Description Set, Knowledge Sharing, Knowledge Owner, Expansion Base>.

(8) Base 8: =< Base ID, Relationship Type, Stability of Relationship Structure, Role, Service Supply Quality of Relationship, Relationship Multilaterality, Expansion Base>.

(9) Base 9: =< Base ID, Class, Name, Adopted Cooperation Strategy, Activeness of Demand Response, Owned Service Resource Set, Resource Value (measured by price), Expansion Base>. 
(10) Base 10: =< Base ID, Class, Name, Adopted Cooperation Strategy, Budget Cost of Obtaining External Resources, Description of Required Service Resources, Expansion Base $>$.

(11) Base 11: =< Base ID, Combination Type, Combination Name, Combination State, Service Path Consistency, Same Service Trigger Time, Service Matching Degree, Expansion Base>.

(12) Base 12: =< Base ID, Class, Frequency of Service Interruption, State of Service Interruption, Effectiveness of Alternatives, Identification of Alternative Collaborators, Expansion Base>.

(13) Base 13 is the same as Base 3

(14) Base 14: =< Base ID, Chain Type, Add Service Flow, Operation State, Location of Service Flow, Acceptance Evaluation, Expansion Base>.

The above is the modeling of the integrated service system. With the change of demand and environment, various agents continuously interact with other agents, and constantly change their behaviors according to their decision-making mechanisms, promoting the continuous evolution of the integrated service system.

\section{SIMULATION}

Based on the proposed multi-agent model, a questionnaire survey was carried out among 380 intelligent manufacturers in the Yangtze River Delta. The survey data are mainly about the following indices: cooperation strategy, business philosophy, commission frequency of producer service, service quality, service acquisition speed, diversity of producer service, stability of service supply-demand network, cooperation capability, and collaboration risk control capability. A total of 380 responses were obtained, including 344 valid ones and 36 invalid ones. Using the valid responses, the backpropagation neural network (BPNN) was introduced to predict the stability of the producer service supply chain. The prediction results are presented in Figure 3.

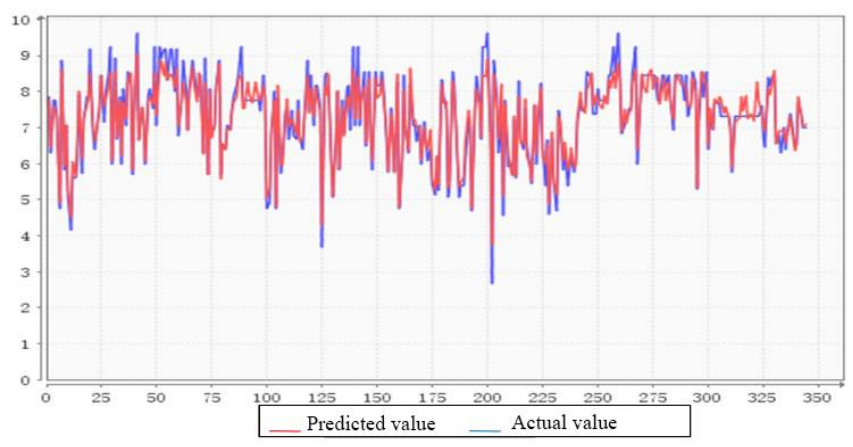

Figure 3. The predicted stability of the producer service supply chain in the Yangtze River Delta

As shown in Figure 3, the predicted stability agrees well with the actual value, indicating that the producer service supply chain in the Yangtze River Delta is well prepared for collaboration operation. Besides, the influence of some collaboration factors on supply chain stability was the same as the design in Figure 2. To some extent, this verifies the feasibility and effectiveness of the proposed model.

\section{CONCLUSIONS}

Facing the intelligent manufacturing cluster in the Yangtze River Delta region, this paper puts forward the idea of integrating the regional productive service resources to supply and demand by the collaborative way dynamically. Based on the theory and literature analysis, the operational relationship between producer services and manufacturing enterprises is clarified. Then, the service Agent and collaborative decisionmaking rules are specially set. Finally, the impact of collaborative factors in agent on the stability of producer service supply chain is explored by simulation of empirical data. The following conclusions are given as the collaborative operation of producer services in the region is feasible, and the coordination mechanism and setting of collaborative factors in this Multi-Agent model have certain effectiveness.

\section{ACKNOWLEDGMENT}

This research was supported by the Natural Science Foundation of Zhejiang Province in China (Grant No.: LY18G010011), The Research Center of Yangtze River Delta integration development Foundation of Jiaxing University (Grant No.: JCSJ201901).

\section{REFERENCES}

[1] Tjahjono, B., Esplugues, C., Ares, E., Pelaez, G. (2017). What does industry 4.0 mean to supply chain? Procedia Manufacturing, $\quad 13$ : 1175-1182. https://doi.org/10.1016/j.promfg.2017.09.191

[2] Li, X.Q. (2017). Research on the influence of Changsha Zhuzhou Xiangtan advanced equipment manufacturing industry cluster on regional economic growth. Hunan Normal University.

[3] Zhu, M., Shao, L. (2020). An analysis on the economic cooperation and the industrial synergy of the main river region: from the perspective of the Yangtze river economic zone. Journal of Ambient Intelligence and Humanized Computing, 11(3): 1055-1064. https://doi.org/10.1007/s12652-018-1011-0

[4] Zhang, Y.Q., Fang, Y. (2016). Synergistic combined effect between producer services and manufacturing in the Yangtze river delta. Technology and Innovation Management, $\quad 37(6)$ : $\quad 657-660, \quad 697$. https://doi.org/10.14090/j.cnki.jscx.2016.0612

[5] Bodrow, W. (2017). Impact of Industry 4.0 in service oriented firm. Advances in Manufacturing, 5(4): 394-400. https://doi.org/10.1007/s40436-017-0196-3

[6] Goldfarb, A., Trefler, D. (2018). AI and international trade. National Bureau of Economic Research, (2): 1-33. https://doi.org/10.3386/w24254

[7] Yu, C.J. (2019). The theoretical framework for developing world-class intelligent manufacturing industry clusters and practice in Chongqing. Journal of Chongqing University of Technology (Social Science) 33(5): 40-48. https://doi.org/10.3969/j.issn.16748425(s).2019.05.005

[8] Europa Inter Cluster. (2011). White paper-The emerging of European world-class clusters. Belgium.

[9] Bialic-Davendra, M.L. (2011). An investigation of a new concept of world-class clusters in Europe-A case study 
of the Visegrad Group of Countries. Journal of Competitiveness, $3(2)$ : 43-57. https://publikace.k.utb.cz/handle/10563/1002720

[10] Wahdan, H.G., Abdelslam, H.E., Abou-El-Enien, T.H.M., Kassem, S.S. (2019). Sustainable product design through non-dominated sorting cuckoo search. Journal Européen des Systèmes Automatisés, 52(5): 439-447. https://doi.org/10.18280/jesa.520502

[11] Faller, C., Feldmüller, D. (2015). Industry 4.0 learning factory for regional SMEs. Procedia Cirp, 32: 88-91. https://doi.org/10.1016/j.procir.2015.02.117

[12] Giret, A., Garcia, E., Botti, V. (2016). An engineering framework for service-oriented intelligent manufacturing systems. Computers in Industry, 81: 116127. https://doi.org/10.1016/j.compind.2016.02.002

[13] Zhen, Y.L. (2019). Enterprise upgrading in emerging economies in the reconstruction of global industrial value chain. Journal of Guangdong University of Administration, 31(6): 95-97.

[14] Cheng, D., Xiao, Z. (2020). Producer services and productivity: A global value chain perspective. Review of Income and Wealth. https://doi.org/10.1111/roiw.12482

[15] Zhou, D., Ying, Y. (2009). Reviews and prospects on the interaction between producer services and manufacturing industries. Journal of Intelligence, 28(8): 200-207. https://doi.org/10.3969/j.issn.1002-1965.2009.08.046

[16] Maull, R., Smart, A., Liang, L. (2014). A process model of product service supply chains. Production Planning \& Control, 25(13-14): 1091-1106. https://doi.org/10.1080/09537287.2013.808840

[17] Francois, J., Woerz, J. (2008). Producer services, manufacturing linkages, and trade. Journal of Industry, Competition and Trade, 8(3-4): 199-229. https://doi.org/10.1007/s10842-008-0043-0

[18] Wen, X., Zhou, X. (2016). Servitization of manufacturing industries based on cloud-based business model and the down-to-earth implementary path. The International Journal of Advanced Manufacturing Technology, 87(5-8): 1491-1508 https://doi.org/10.1007/s00170-014-6348-8

[19] Johnson, M., Mena, C. (2008). Supply chain management for servitised products: A multi-industry case study. International Journal of Production Economics, 114(1): 27-39. https://doi.org/10.1016/j.ijpe.2007.09.011

[20] Baines, T., Lightfoot, H., Peppard, J., Johnson, M., Tiwari, A., Shehab, E., Swink, M. (2009). Towards an operations strategy for product-centric servitization. International Journal of Operations \& Production Management, 295(5): 494-519. https://doi.org/10.1108/01443570910953603

[21] Lockett, H., Johnson, M., Evans, S., Bastl, M. (2011). Product Service Systems and supply network relationships: an exploratory case study. Journal of Manufacturing Technology Management, 22(3): 293313. https://doi.org/10.1108/17410381111112684

[22] Schmenner, R.W. (2009). Manufacturing, service, and their integration: some history and theory. International Journal of Operations \& Production Management, 29(5): 431-334. https://doi.org/10.1108/01443570910953577

[23] Zimmer, K. (2002). Supply chain coordination with uncertain just-in-time delivery. International Journal of Production Economics, 77(1): 1-15. https://doi.org/10.1016/S0925-5273(01)00207-9

[24] Giri, B.C., Sarker, B.R. (2016). Coordinating a twoechelon supply chain under production disruption when retailers compete with price and service level. Operational Research, 16(1): 71-88. https://doi.org/10.1007/s12351-015-0187-8

[25] Frascatore, M.R., Mahmoodi, F. (2008). Long-term and penalty contracts in a two-stage supply chain with stochastic demand. European Journal of Operational Research, $\quad 184(1)$ : 147-156. https://doi.org/10.1016/j.ejor.2006.10.056

[26] Samaddar, S., Kadiyala, S.S. (2006). An analysis of interorganizational resource sharing decisions in collaborative knowledge creation. European Journal of Operational Research, 170(1): 192-210. https://doi.org/10.1016/j.ejor.2004.06.024

[27] Yu, H., Sun, C., Chen, J. (2007). Simulating the supply disruption for the coordinated supply chain. Journal of Systems Science and Systems Engineering, 16(3): 323335. https://doi.org/10.1007/s11518-007-5045-7

[28] Boyaci, T., Gallego, G. (2004). Supply chain coordination in a market with customer service competition. Production and Operations Management, 13(1): $\quad 3-22 . \quad$ https://doi.org/10.1111/j.19375956.2004.tb00141.x

[29] Lee, P.D. (2006). Port supply chains as social networks. In 2006 IEEE International Conference on Service Operations and Logistics, and Informatics, pp. 10641069. https://doi.org/10.1109/SOLI.2006.328899

[30] Shettigar, A.K., Patel, G.M., Chate, G.R., Vundavilli, P.R., Parappagoudar, M.B. (2020). Artificial bee colony, genetic, back propagation and recurrent neural networks for developing intelligent system of turning process. SN $\begin{array}{lll}\text { Applied } & \text { Sciences, } & \text { 2(4): }\end{array}$ https://doi.org/10.1007/s42452-020-2475-z

[31] Epstein, J.M. (2006). Generative Social Science: Studies in Agent-Based Computational Modeling. Princeton University Press.

[32] Bonabeau, E. (2002). Agent-based modeling: Methods and techniques for simulating human systems. Proceedings of the National Academy of Sciences, 99(suppl 3): 7280-7287. https://doi.org/10.1073/pnas.082080899

[33] Baxter, N., Collings, D., Adjali, I. (2003). Agent-based modelling-intelligent customer relationship management. BT Technology Journal, 21(2): 126-132. https://doi.org/10.1023/A:1024455405112

[34] Hsieh, F.S. (2019). Dynamic configuration and collaborative scheduling in supply chains based on scalable multi-agent architecture. Journal of Industrial Engineering International, 15(2): 249-269. https://doi.org/10.1007/s40092-018-0291-5 